\title{
BMJ Open Anticancer drug prices and clinical outcomes: a cross-sectional study in Italy
}

\author{
Francesco Trotta, ${ }^{1}$ Flavia Mayer, ${ }^{2}$ Francesco Barone-Adesi, ${ }^{3}$ Immacolata Esposito, ${ }^{4}$ \\ Ranadhir Punreddy, ${ }^{3}$ Roberto Da Cas, ${ }^{5}$ Giuseppe Traversa, ${ }^{5}$ Francesco Perrone, ${ }^{6}$ \\ Nello Martini, ${ }^{4}$ Bishal Gyawali, ${ }^{7}$ Antonio Addis (i) ${ }^{1}$
}

To cite: Trotta F, Mayer F, Barone-Adesi F, et al. Anticancer drug prices and clinical outcomes: a cross-sectional study in Italy. BMJ Open 2019;9:e033728. doi:10.1136/ bmjopen-2019-033728

- Prepublication history and additional material for this paper are available online. To view these files, please visit the journal online (http://dx.doi. org/10.1136/bmjopen-2019033728).

Received 19 August 2019 Revised 10 November 2019 Accepted 11 November 2019

Check for updates

(c) Author(s) (or their employer(s)) 2019. Re-use permitted under CC BY-NC. No commercial re-use. See rights and permissions. Published by BMJ.

${ }^{1}$ Department of Epidemiology of the Regional Health Service Lazio, Rome, Italy

${ }^{2}$ National Center for Disease

Prevention and Health

Promotion, Italian National Institute of Health, Italy

${ }^{3}$ Università del Piemonte Orientale Amedeo Avogadro,

Novara, Italy

${ }^{4}$ Research and Health Foundation, Roma, Italy

${ }^{5}$ National Centre for

Epidemiology, Italian National Institute of Health, Rome, Italy ${ }^{6}$ Istituto Nazionale Tumori IRCCS Fondazione Pascale, Napoli,

Campania, Italy

${ }^{7}$ Harvard Medical School, Boston, UK

Correspondence to

Dr Antonio Addis;

agmaddis@gmail.com

\section{ABSTRACT}

Objective To investigate whether the prices of new anticancer drugs correlated with their relative benefit despite negotiation.

Design Retrospective cross-sectional study correlating new anticancer drugs prices with clinical outcomes. Setting We did a retrospective cross-sectional study including all new anticancer drugs approved by the European Medicines Agency (EMA) (2010-2016) and reimbursed in Italy.

Main outcome(s) and measure(s) Information on clinical outcomes-in terms of median overall survival (OS), median progression-free survival (PFS) and objective response rate $(\mathrm{ORR})$ - was extracted from pivotal trials as reported in the European Public Assessment Reports available on the EMA website. Cost of a full course treatment was estimated on negotiated official and discounted prices. Regression coefficients $\beta$, their levels of significance $p$ and the coefficients of determination $R^{2}$ were estimated adjusting by tumour type.

Results Overall, 30 new anticancer drugs (with 35 indications) were available for analysis. Where data on OS were available, we observed no correlation between the improvement in median OS (in weeks) and negotiated price $\left(R^{2}=0.067, n=16\right.$ drugs for 17 indications). When the clinical outcomes were expressed as improvements in the median PFS or ORR, 25 drugs (29 indications) were available for the analysis, and again, there was no correlation with prices ( $R^{2}=0.004$ and 0.006 , respectively). Conclusions and relevance Our results suggest that the prices of anticancer drugs in Italy do not reflect their therapeutic benefit. Drug price negotiations, which is mandatory by law in Italy, do not seem to ensure that prices correlate with clinical benefits provided by the cancer drugs. These results call for further efforts to establish the standard determinants of drug prices available at the time of negotiation. These findings need to be confirmed in other countries where price negotiations are in place. Moreover, further investigations may verify whether outcome data obtained after drug marketing would improve the correlation between prices and therapeutic benefit.

\section{BACKGROUND}

High costs of cancer drugs and resulting financial toxicity to cancer patients are now

\section{Strengths and limitations of this study}

- This study is the first attempt to evaluate whether there were better correlations between cancer drug prices and clinical outcomes in a setting where central price negotiations are mandatory for every new medicine.

- This understanding is important for cancer policy decisions.

- In our analysis, the relationship between the clinical outcome and cost of anticancer drugs was ascertained by a simple linear regression model.

- Clinical outcome, which was the dependent variable, was expressed as absolute or per cent differences in outcomes between treatment and control groups.

- The main limitations of our study concern data completeness on clinical outcome and price. We used, as an estimate of benefit, data from pivotal trials retrieved from European Public Assessment Reports.

a well-recognised problem in cancer policy throughout the world. ${ }^{1-8}$ Various solutions are being proposed to address this problem, of which price negotiations with pharmaceutical companies are proposed as an important strategy, especially in the USA. ${ }^{9-11}$ Because the Medicare is not allowed to negotiate prices with companies, despite being mandated to cover for every US Food and Drug Administration (FDA)-approved drug, various experts have argued that this is the reason for high drug prices in the USA. Indeed, cancer drug prices far exceed the costs of their development ${ }^{12}$; such negotiations might help to lower the prices of cancer drugs as evidenced by lower cost of cancer drugs in other developed countries compared with the USA.

However, little is known about if such negotiations would lead to better correlation between cancer drug prices and the benefits they provide. Studies have shown that drug prices do not correlate with clinical benefits for cancer drugs approved by the FDA, even though such studies have not taken central 
price negotiations into account. ${ }^{13} 14$ Countries, such as the UK and Italy, negotiate prices and hence, the correlations might be different.

In Italy, drug price negotiation based on costeffectiveness evaluation has been mandatory since 2001 for all medicines reimbursed by the National Health Service (NHS) ${ }^{1516}$ We analysed the correlation between the prices of cancer drugs in Italy with their clinical outcomes to test the hypothesis that central price negotiations lead to better alignment of prices and benefits.

\section{METHODS}

\section{Identification of the study sample}

All new drugs approved by the European Medicines Agency (EMA) via a centralised procedure between January 2010 and June 2016 for the treatment of either solid or haematological cancers were initially identified. Generics, biosimilars, interferons and granulocyte-colony stimulating factors were excluded. Only anticancer drugs with pivotal trials based on overall survival (OS), progression-free survival (PFS) or objective response rate (ORR) and with prices that were officially negotiated in Italy by 31 December 2016 were included in the cohort for analyses.

\section{Data extraction}

Information on the clinical outcomes (in terms of median OS, median PFS and ORR) was extracted by two coinvestigators (FB-A and RP) from pivotal trials that compared new treatments with controls as reported in the European Public Assessment Reports (EPARs) (summary table of the main study, Section 2.5.2) publicly available on the EMA website (www.ema.europa.eu). Survival times were expressed in weeks, and the reported OS and PFS were transformed when necessary. Information on therapeutic indication and tumour type were also retrieved.

\section{Drug prices}

The cost of a full course or 1-year treatment was estimated by two coinvestigators (NM and IE) on the basis of the negotiated official ex-factory price (in euros) of drug packages, as published in the Official Gazette of the Italian Republic (www.gazzettaufficiale.it) and taking into account the posology as reported in the summary of product characteristics (SPC). To compare prices of drugs with different schedules, in the text, we refer to drug prices as the cost of a full course or a 1-year treatment. A further estimate took into account additional compulsory rebates ${ }^{17}$ or extradiscounts that were agreed with pharmaceutical companies; this information is confidential to the public but is released to procurement stations within the Italian NHS (eg, regions, hospitals and local health units).

\section{Statistical analysis}

The following variables were extracted and analysed descriptively: year of approval, therapeutic indication, type of treatment and control groups, outcome data, official and confidential costs per treatment (1 year or a full course) and regulatory information (conditional/under exceptional circumstances approval or orphan drug status).

The relationship between the clinical outcomes and cost of anticancer drugs was ascertained by a simple linear regression model. Clinical outcome, which was the dependent variable, was expressed as absolute or percent differences in outcomes between treatment and control groups. Regression coefficients $\beta$, their levels of significance $p$ and the coefficients of determination $R^{2}$ were reported for each model.

We also performed several sensitivity analyses to test the robustness of the results. Specifically, we performed multiple linear regression with tumour type as the independent variable to take into account potential differences due to tumour characteristics. Moreover, we also repeated the analysis after excluding negative outcome differences (in two cases, one of the outcomes was inferior in the group receiving the new drug than in the comparison group) and actively controlled trials (considering only placebo-controlled trials). Subgroup analysis by tumour type was also attempted as exploratory analysis when a minimum number of two anticancer drugs within the same tumour type setting were observed. Outlier cases were not excluded from the analyses, but their impact was evaluated and reported when relevant as a separate analysis. All statistical analyses were performed using STATA (StataCorp, V.14.0)

\section{Patient and public involvement}

Patients have not been involved in the development of the research question or the design of this study. However, results of this analysis will be disseminated throughout public conferences, with statements summarising our results, and with an open access to the published report posted in our institutional websites

\section{RESULTS}

From 2010 to mid-2016, 45 new anticancer drugs for 56 different oncology indications were approved via centralised procedures by the EMA. For 40 new anticancer drugs (47 indications), the basis for the approval was a pivotal trial adopting OS, PFS or ORR as a primary outcome; the price negotiation was completed by December 2016 for only 30 new anticancer drugs (35 indications) which are included in our analysis (table 1 ). Seven drugs received orphan drug status by the EMA and two (vandetanib and crizotinib) received conditional approval. Of the 35 oncology indications tested in 35 different pivotal trials which were all controlled clinical trials, the most common indications were melanoma ( 7 out of 35), followed by haematological cancer (6 out of 35 ) and non-small-cell lung cancer (4 out of 35). In 15 such trials $(43 \%)$, placebo was used as the control arm. Of the 35 indications, data on OS, PFS and ORR were 


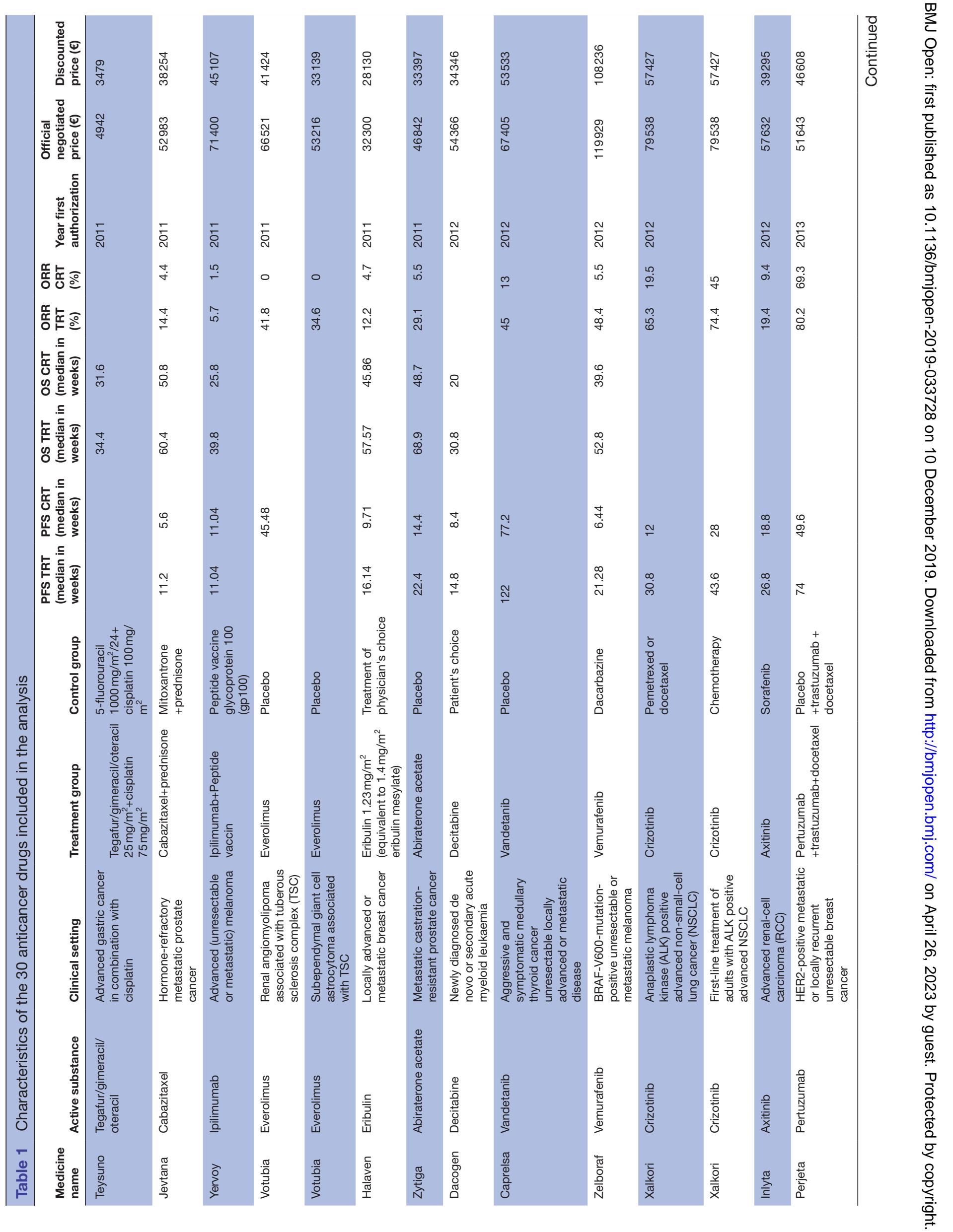




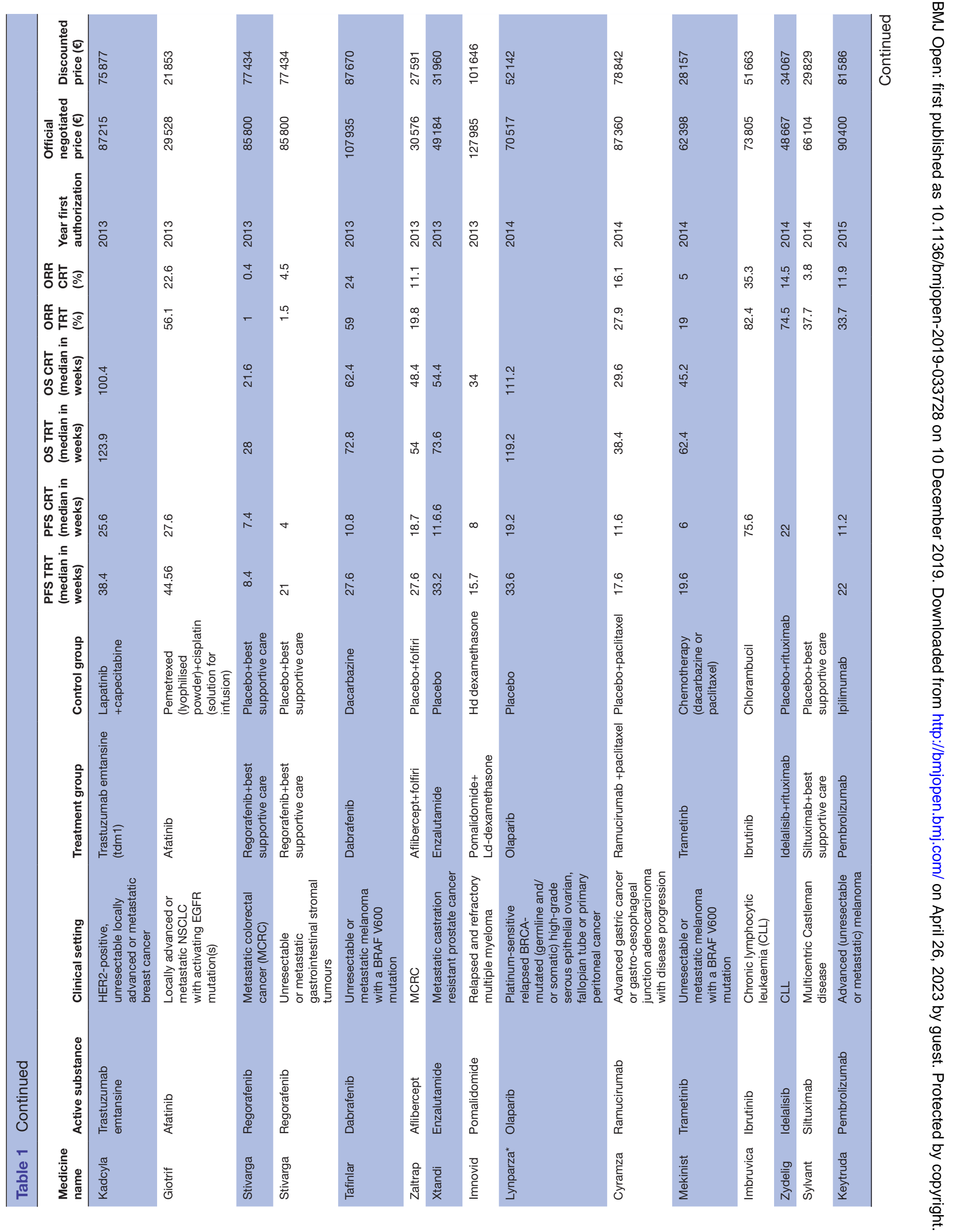




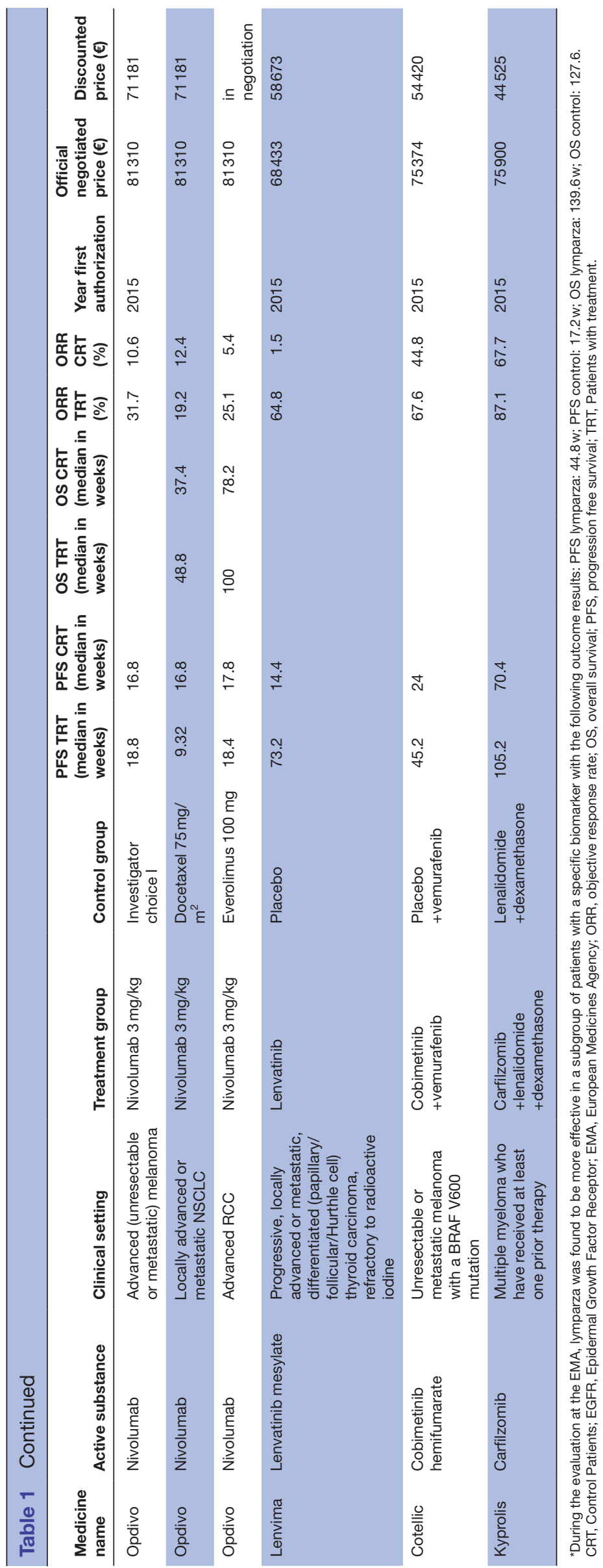




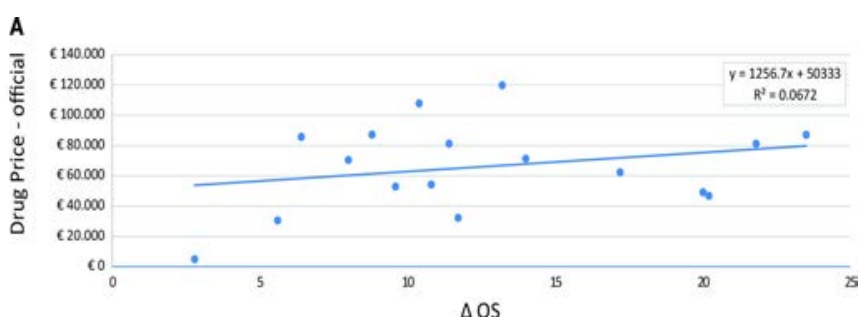

B

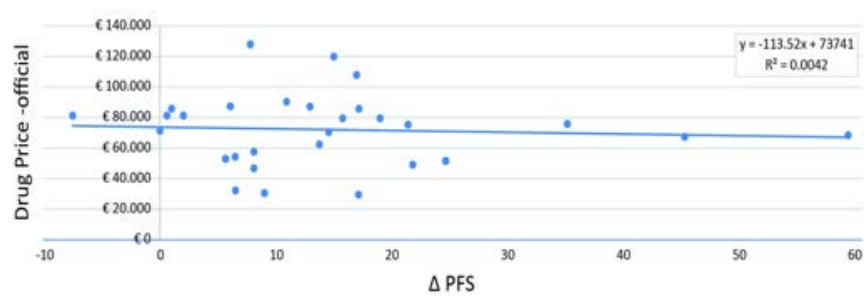

c

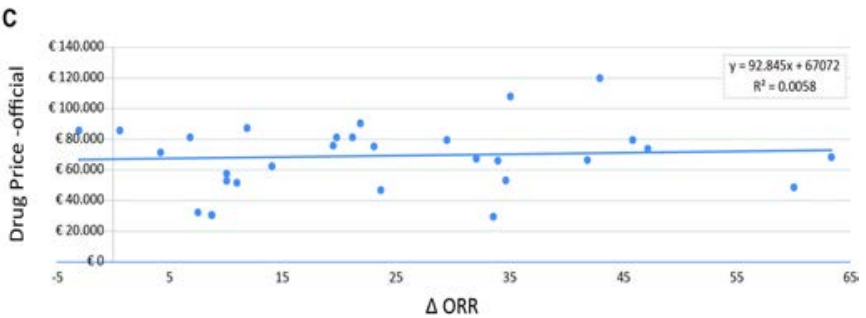

Figure 1 Correlation between anticancer drug prices (officially negotiated) and health benefits. (A) Official negotiated price (ex-factory) versus difference in median OS (16 drugs are included in the analysis: 15 with a single indication and 1 with two indications). (B) Official negotiated price (ex-factory) versus difference in median PFS (25 drugs are included in the analysis: 22 with a single indication, 2 with two indications and 1 with three indication). (C) Official negotiated price (ex-factory) versus proportion of ORR (24 drugs are included in the analysis: 20 with a single indication, 3 with two indications and 1 with three indications). OS, overall survival; ORR, objective response rate; PFS, progression-free survival.

available for 17, 29 and 29 indications, respectively. Each drug-indication pair contributed to one or more of these analyses, depending on which outcomes were reported in the EPAR.

In the treatment groups, the median improvements in the OS and PFS were 11.4 weeks (IQR 8.8-17.2; min 13.2; $\max 23.5$ ) and 12.8 weeks (IQR 6.4-17; min -7.48; max 58.8), respectively; median ORR improvement in the treatment group was $21.8 \%$ (IQR 10-34.6; min -3; $\max 63.3)$. The reported ranges have negative minimum values since in two cases-nivolumab for NSCLC and regorafenib for gastrointestinal stromal tumours-the experimental treatment had a negative effect on one of the outcomes compared with the control group (in terms of PFS for nivolumab and ORR for regorafenib). The median negotiated price for a 1-year treatment was $€ 72392$ (IQR 53,819-85,800; $\min 4,942$; $\max 142,785$ ), which was further discounted by $25 \%$ (on average) after applying confidential rebates. For all anticancer drugs but ipilimumab the price was calculated as 1-year treatment since the posology reported in the SPC reported that the treatment should continue as long as clinical benefit is observed or until unacceptable toxicity occurs. In the case of ipilimumab, the price was calculated as a course of four doses as reported in the SPC.

The official (ex-factory) price of new anticancer drugs and absolute clinical outcomes showed no correlation (figure 1A-C). The relationship between the improvement in median OS (in weeks) and negotiated price was estimated for 16 drugs (17 indications), and no correlation was observed $\left(\mathrm{R}^{2}=0.067\right)$. When clinical outcomes were expressed as absolute advantage in median PFS or ORR, 25 drugs (29 indications) were available for analysis, and in these cases, no correlation was observed $\left(R^{2}=0.004\right.$ and 0.006 , respectively).

Repeating the analyses and taking into account the additional confidential rebates, which are compulsory for hospital procurement, no improvement in the benefit/ price relationships was highlighted (figure 2A-C). These findings also remained unchanged when the analyses were repeated with adjustments for tumour type (online supplementary table 1) or when clinical outcome was expressed as a percentage of improvement instead of as an absolute difference (online supplementary figure 1a-c). Sensitivity analyses that excluded negative improvements in outcomes over a control group (online supplementary figure 2) and considered only data from placebocontrolled trials (online supplementary figure 3a,b) confirmed the main analysis. The exploratory subgroup analyses by tumour type did not identify specific positive correlation patterns depending on tumour setting (online supplementary figure 4A,B).

\section{DISCUSSION}

This study is the first attempt to evaluate whether there were better correlations between cancer drug prices and clinical outcomes in a setting where central price negotiations are mandatory for every new medicine. Our study gave unexpected results to the research question, highlighting no relationships between cost of cancer drugs and benefits. Moreover, all prespecified sensitivity and subgroup analyses confirmed the main findings. This finding will have important policy implications both for countries like USA where price negotiations are absent and for other countries like Italy where price negotiations do exist.

In our study, the correlation between drug costs and clinical outcomes was even lower than the ones previously noted in the US context, ${ }^{1314}$ showing that negotiations did not tilt the relationship between drug prices and benefit positively. Thus, higher drug pricing remains despite the Italian legislative environment, where approval based on cost-effectiveness analysis and price negotiations have been mandatory by law since $2001 .^{1516}$ This finding may cast doubts on the role of the negotiation itself. However, it is important to understand that countries like Italy that negotiate drug prices do such negotiations only for binary decisions of approval or no-approval, not taking into 
A
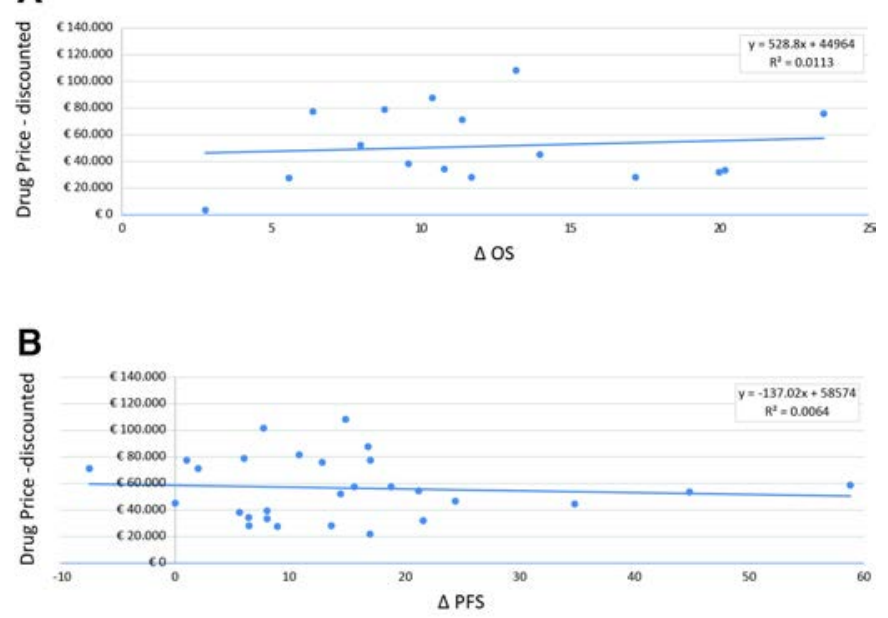

\section{C}

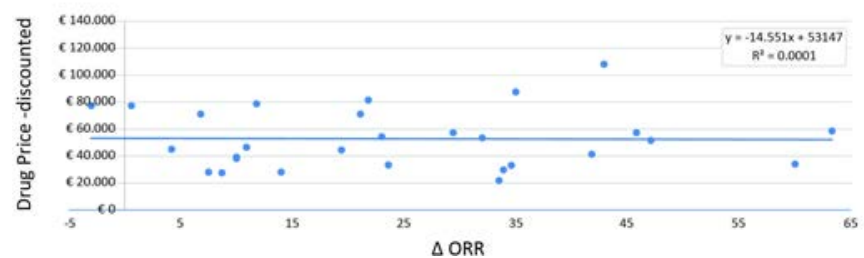

Figure 2 Correlation between anticancer drug prices (discounted) and health benefits. (A) Discounted price with additional compulsory rebates versus difference in median OS (16 drugs related to a single indication are included in the analysis). (B) Discounted price with additional compulsory rebates versus difference in median PFS (25 drugs are included in the analysis: 22 with a single indication and 3 with two indications). (C) Discounted price with additional compulsory rebates versus proportion of ORR (24 drugs are included in the analysis: 20 with a single indication and 4 with two indications). OS, overall survival; ORR, objective response rate; PFS, progression-free survival.

account, during negotiation, a clear correlation between prices and benefits. This understanding is important for cancer policy decisions.

Indeed, there is no legal policy in any country to negotiate prices differently for drugs approved on the basis of surrogate endpoints versus survival outcomes, or drugs that improve survival in days, versus those that improve survival in months or drugs with immature benefit risk profiles. ${ }^{18-22}$ Although steps in the right direction, in lack of such policy, the value frameworks proposed by organisations such as ASCO, ESMO or NCCN have become little more than intellectual exercises. ${ }^{23-26}$

Another reason price negotiations did not achieve better price-value correlations is that because of the global market of drugs, each single country-although large-only represents a small portion of the consumer market. Thus, companies 'wield the stick', setting the maximum price that the market will bear. ${ }^{27}$ In addition, in Italy, no threshold for incremental cost-effectiveness ratio (ICER) has been determined; thus, no limit is in place to be used as a decision rule in resource allocation at the time of negotiation/reimbursement decisions. The lack of such kind of cut-off might have contributed to the negative results in our study. However, we recognise that even when a threshold for ICER is well established, such as in the $\mathrm{UK},{ }^{28}$ continuous exceptions have been allowed in the case of anticancer drugs. For example, an ad hoc fund established in 2010 (ie, the Cancer Drug Fund) was recently dismissed by the Parliament because it did not deliver meaningful value to patients or society. ${ }^{29}$

In the EU context (where newer anticancer drugs are approved by EMA without considering the added-value or cost-effectiveness), the complexity further increases because once a marketing authorisation is granted, it may become difficult to manage the reimbursement issue at a national level. ${ }^{30}$ Moreover, it is also difficult for payers (NHS/insurance) to defend the thesis against the public opinion that an anticancer drug cannot be reimbursed because it is too expensive. ${ }^{30} 31$ Indeed, as our study shows, the confidential discounts following negotiations between a member state and a company do not ameliorate the correlation between treatment costs and benefits even though they reduce absolute drug prices.

Another factor that negatively influences the contractual power of negotiation is non-transparent information on drug prices across countries. Difficulties in retrieving full information on prices have been already recognised in a recent survey comparing prices of anticancer drugs in 16 EU countries, Australia and New Zealand. ${ }^{32}$ Vogler et al found that price information is scarce and not disclosed due to confidential discounts or managed entry agreements (MEAs), calling for higher transparency. The authors state that it is in the interest of policy-makers to remove clauses limiting disclosure on price information because they risk overpaying when setting prices through external price referencing. This concern might be relevant in the Italian context since the negotiation procedure for reimbursement takes into account the price in other EU countries as well as the price of similar products within the same pharmacotherapeutic group. ${ }^{33}$

We believe that two partly independent approaches could be adopted by policy-makers to achieve a better balance between cancer drug prices and benefits. First, price negotiations should be more strictly based on the level of evidence as well as the magnitudes of benefit. An ICER measure (such as QALY) should represent a threshold for reimbursement, thus setting a starting point for price negotiation and adjusting the ICER threshold based on the magnitude of the relative benefit reached. If the information on the relative value is not available at the time of approval, comparisons can be performed using indirect techniques, whereas after entering the market, payers should play a major role in supporting the evidence generating process.

The second approach that could attain lower prices would require an increased transparency on the costs of drug development process, including the relative contributions from academia and public sector to the development of a drug. ${ }^{34-38}$ For instance, research conducted 
to evaluate efforts of drug development processes highlighted that about half of the most transformative drugs approved by the FDA had substantial contributions to their development by academic researchers supported by government funding ${ }^{34}{ }^{35}$; in addition, it has been estimated that the cost of late clinical development takes a limited part of the whole process. ${ }^{36}$ It is probably the right time to appropriately acknowledge the contributions of publicly funded research during drug price negotiation with companies. Often, comparative effectiveness research is funded by public institutions to test different treatments in real practice on robust outcomes with longer follow-up or special populations. ${ }^{37} 38$ The findings of these studies should be linked to a continuous price renegotiation over the life cycle of a product.

Other approaches identified as possible solutions to keep the health system sustainable address the general governance of the system, that is, when the price is already set. In fact, a price-volume approach $^{39}$ or indicationbased pricing ${ }^{40}{ }^{41}$ have been modelled, each presenting pros and cons. Moreover, given that different oncology settings appear to be oligopolistic, thus refraining from price competition, another possible solution comes from national/regional tenders among therapeutic categories when more alternatives are available. ${ }^{42}$

The main limitations of our study concern data completeness on clinical outcome and price. We used, as an estimate of benefit, data from pivotal trials retrieved from EPARs. Moreover, we are not aware if further (more robust) data became available at a later stage when the price was negotiated at the national level. Thus, we cannot exclude that the correlation between drug prices and therapeutic benefit might improve taking into account data acquired after the marketing of anticancer drugs.

Another important limitation is that we have not considered quality of life outcomes as another metric of clinical benefit. Furthermore, a recent study has shown that quality of life outcomes are not routinely collected or published, and that the tools used to measure quality of life are varied to have a uniform metric for comparison. ${ }^{43}$ Although we have included surrogate measures such as PFS or ORR as clinical outcomes in our analysis because they were considered as the basis for approval by the regulatory agency, these surrogate measures do not always correlate with true clinical benefits in terms of improved survival or improved quality of life. ${ }^{43} 44$ Regarding the price estimate, we estimated the treatment costs for 1-year treatment or for the total course in the case of ipilimumab where the treatment course lasts less than 1 year. However, the exclusion of ipilimumab would not alter the main findings.

Another factor that might have impacted the price estimation is the rebate obtained at the regional/local level following drug tenders. This information was not available for the analyses and would have been not generalisable at the national level. Moreover, additional savings were expected 'a posteriori' from the MEAs in place in
Italy (whose information is not publicly available) and were not considered in the analyses.

Our study is a retrospective cross-sectional correlation study that aimed at evaluating whether central price negotiation (mandatory by law in Italy) leads to better alignment of prices and the benefits known at the time of drug approval. This means that our analysis is not aimed at comparing costs and outcomes within drug classes, as a typical cost-effective study, and we never intended to assess the added values of the approved drugs in the context of all other drugs sharing the same indication. The 'population'/cohort approach that we adopted has the intrinsic limitation of including drugs approved for different indications or different cancer types (with various incidence/prevalence) based on different clinical data packages. The consequent heterogeneity stemming from this approach was resolved adjusting the correlation analyses by tumour type or conducting several subanalyses. Following this approach, we found results consistent with primary findings thus confirming the robustness of methods and results.

\section{CONCLUSION}

Our results suggest that price negotiations for approval decisions alone may not bring balance between prices and benefits of anticancer drugs. Based on the limited outcome data available at the time of reimbursement decisions (OS, PFS and ORR), prices of anticancer drugs do not reflect their therapeutic benefit. Other strategies, such as value-based price negotiations, price negotiations strictly based on strength of evidence and price transparencies may be necessary to better achieve the drug prices and benefits balance. These results need to be confirmed in other countries where a national price negotiation exists.

Contributors FT, NM and AA conceptualised the study. FT, AA, NM, FM, FB-A, GT and RDC designed the study. FB-A, RP, IE and NM were in charge of data extraction and quality control. FM, RDC and FT performed the data analysis. FT, RDC, FM, GT, $\mathrm{BG}, \mathrm{FP}$ and $\mathrm{AA}$ drafted the manuscript; all the authors contributed to the discussion and the interpretation of results and reviewed the final version of the manuscript. All authors approved the final manuscript as submitted.

Funding The authors have not declared a specific grant for this research from any funding agency in the public, commercial or not-for-profit sectors.

Competing interests FP has received personal fees unrelated to the work presented in this article from Bayer, Ipsen, Astra Zeneca, Bristol Myers Squibb, Sandoz, Incyte, Celgene, Pierre Fabre, Janssen-Cilag.

Patient consent for publication Not required.

Provenance and peer review Not commissioned; externally peer reviewed.

Data availability statement All data relevant to the study are included in the article or uploaded as online supplementary information.

Open access This is an open access article distributed in accordance with the Creative Commons Attribution Non Commercial (CC BY-NC 4.0) license, which permits others to distribute, remix, adapt, build upon this work non-commercially, and license their derivative works on different terms, provided the original work is properly cited, appropriate credit is given, any changes made indicated, and the use is non-commercial. See: http://creativecommons.org/licenses/by-nc/4.0/.

ORCID iD

Antonio Addis http://orcid.org/0000-0003-0962-9959 


\section{REFERENCES}

1 Quintiles IMS Institute. Outlook for global medicines through 2021, 2016. Available: http://www.imshealth.com/en/thought-leadership/ quintilesims-institute/reports/outlook_for_global_medicines_through 2021

2 Ghinea N, Lipworth W, Kerridge I. Propaganda or the cost of innovation? challenging the high price of new drugs. BMJ 2016;352.

3 European Commission - Press release. Antitrust: Commission opens formal investigation into aspen pharma's pricing practices for cance medicines. Brussels, 2017. Available: http://europa.eu/rapid/pressrelease_IP-17-1323 en.htm

4 Gordon N, Stemmer SM, Greenberg D, et al. Trajectories of injectable cancer drug costs after Launch in the United States. J Clin Oncol 2018;36:319-25.

5 Narang AK, Nicholas LH. Out-Of-Pocket spending and financial burden among Medicare beneficiaries with cancer. JAMA Oncol 2017:3:757-65.

6 Shankaran V, Ramsey S. Addressing the Financial Burden of Cancer Treatment: From Copay to Can't Pay. JAMA Oncol 2015;1:273-4.

7 Szabo L. Cancer patients skipping medicines or delaying treatment due to high drug prices. STAT 2017;15.

8 de Souza JA, Conti RM. Mitigating financial toxicity among US patients with cancer. JAMA Oncol 2017;3:765-6.

9 Kesselheim AS, Avorn J, Sarpatwari A. The high cost of prescription drugs in the United States: origins and prospects for reform. JAMA 2016;316:858-71.

10 Hwang TJ, Kesselheim AS, Sarpatwari A. Value-Based pricing and state reform of prescription drug costs. JAMA 2017;318:609-10.

11 Fralick M, Avorn J, Kesselheim AS. The price of crossing the border for medications. N Engl J Med 2017;377:311-3.

12 Tay-Teo K, Ilbawi A, Hill SR. Comparison of sales income and research and development costs for FDA-approved cancer drugs sold by Originator drug companies. JAMA Netw Open 2019;2:e186875

13 Mailankody S, Prasad V. Five years of cancer drug approvals: innovation, efficacy, and costs. JAMA Oncol 2015;1:539-40.

14 Vivot A, Jacot J, Zeitoun J-D, et al. Clinical benefit, price and approval characteristics of FDA-approved new drugs for treating advanced solid cancer, 2000-2015. Ann Oncol 2017;28:1111-6.

15 Comitato Interministeriale per la Programmazione Economica. Individuazione dei criteri per La contrattazione del prezzo dei farmaci (Deliberazione n.3/2001). official Gazette of the Italian Republic. N. 73 del 28-03-2001. Available: http://www.gazzettaufficiale.it/eli/id/2001/ 03/28/001A3188/sg

16 Italian Parliament. Legge 24 novembre 2003, N. 326. Conversione in Legge, Con modificazioni, del decreto-legge 30 settembre 2003 , N. 269, recante disposizioni urgenti per favorire lo sviluppo E per La correzione dell'andamento dei conti pubblici. official Gazette of the Italian Republic. N. 274, 2003. Available: http://www.parlamento.it/ parlam/leggi/03326l.htm

17 Italian Parliament. Legge 27 December 2006, N. 296. art. 1 CoMMA 796, lettera G). Disposizioni per La formazione del bilancio annuale $E$ pluriennale dello Stato (finanziaria 2007). official Gazette of the Italian Republic. N. 299; 27 December 2006, Suppl ord. N. 244.

18 Apolone G, Joppi R, Bertele' V, et al. Ten years of marketing approvals of anticancer drugs in Europe: regulatory policy and guidance documents need to find a balance between different pressures. Br J Cancer 2005;93:504-9.

19 Bertele' V, Banzi R, Capasso F, et al. Haematological anticancer drugs in Europe: any added value at the time of approval? Eur $\mathrm{J}$ Clin Pharmacol 2007;63:713-9.

20 Trotta F, Apolone G, Garattini S, et al. Stopping a trial early in oncology: for patients or for industry? Ann Oncol 2008;19:1347-53.

$21 \mathrm{Kim}$ C, Prasad V. Cancer drugs Approved on the basis of a surrogate end point and subsequent overall survival: an analysis of 5 years of US food and drug administration approvals. JAMA Intern Med 2015;175:1992-4.

22 Banzi R, Gerardi C, Bertele' V, et al. Approvals of drugs with uncertain benefit-risk profiles in Europe. Eur J Intern Med 2015;26:572-84.

23 Salas-Vega S, lliopoulos O, Mossialos E. Assessment of overall survival, quality of life, and safety benefits associated with new cancer medicines. JAMA Oncol 2017;3:382-90.

24 Wise PH. Cancer drugs, survival, and ethics. BMJ 2016;355.

25 Del Paggio JC, Sullivan R, Schrag D, et al. Delivery of meaningful cancer care: a retrospective cohort study assessing cost and benefit with the ASCO and ESMO frameworks. Lancet Oncol 2017;18:887-94.

26 Sobrero A, Bruzzi P. Incremental advance or seismic shift? the need to raise the bar of efficacy for drug approval. JCO 2009;27:5868-73.

27 Ramsey SD, Lyman GH, Bangs R. Addressing skyrocketing cancer drug prices comes with tradeoffs. JAMA Oncol 2016;2:425-6.

28 Dillon A. Carrying NICE over the threshold. NICE, 2015. Available: https://www.nice.org.uk/news/blog/carrying-nice-over-the-threshold

29 Aggarwal A, Fojo T, Chamberlain C, et al. Do patient access schemes for high-cost cancer drugs deliver value to society? lessons from the NHS Cancer Drugs Fund. Ann Oncol 2017:28:1738-50.

30 Cohen D. Cancer drugs: high price, uncertain value. BMJ 2017;359.

31 Prasad V. Do cancer drugs improve survival or quality of life? BMJ 2017;359.

32 Vogler S, Vitry A, Babar Z-U-D. Cancer drugs in 16 European countries, Australia, and New Zealand: a cross-country price comparison study. Lancet Oncol 2016;17:39-47.

33 Folino-Gallo P, Montilla S, Bruzzone M, et al. Pricing and reimbursement of pharmaceuticals in Italy. Eur $\mathrm{J}$ Health Econ 2008;9:305-10.

34 Stevens AJ, Jensen JJ, Wyller K, et al. The role of public-sector research in the discovery of drugs and vaccines. $N$ Engl $J$ Med 2011;364:535-41.

35 Kesselheim AS, Tan YT, Avorn J. The roles of academia, rare diseases, and repurposing in the development of the most transformative drugs. Health Aff 2015;34:286-93.

36 Martin L, Hutchens M, Hawkins C, et al. How much do clinical trials cost? Nat Rev Drug Discov 2017;16:381-2.

37 Italian Medicines Agency (AIFA) Research \& Development Working Group. Feasibility and challenges of independent research on drugs: the Italian medicines Agency (AIFA) experience. Eur J Clin Invest 2010;40:69-86.

38 Traversa G, Masiero L, Sagliocca L, et al. Italian program for independent research on drugs: 10 year follow-up of funded studies in the area of rare diseases. Orphanet J Rare Dis 2016:11:36.

39 Messori A. Application of the Price-Volume approach in cases of innovative drugs where value-based pricing is inadequate: description of real experiences in Italy. Clin Drug Investig 2016;36:599-603.

40 Bach PB. Indication-Specific pricing for cancer drugs. JAMA 2014;312:1629-30.

41 Chandra A, Garthwaite C. The economics of Indication-Based drug pricing. N Engl J Med 2017;377:103-6.

42 Kantarjian H, Rajkumar SV. Why are cancer drugs so expensive in the United States, and what are the solutions? Mayo Clinic Proceedings 2015;90:500-4.

43 Hwang TJ, Gyawali B. Association between progression-free survival and patients' quality of life in cancer clinical trials. Int $J$ Cancer 2019;144:1746-51.

44 Prasad V, Kim C, Burotto M, et al. The strength of association between surrogate end points and survival in oncology: a systematic review of Trial-Level meta-analyses. JAMA Intern Med 2015;175:1389-98. 